cases, which come later under the observation of ophthalmic surgeons, of irreparable injury to sight accruing from the inability of the optician to discriminate between refractive error and disease.

The greater portion of the Council's report deals with the question at issue; appended thereto is a brief historical account of the science and art of refraction, and of the origin of spectacles.

The status of sight-testing opticians has also been discussed by the Departmental Committee of the Ministry of Health on "The Causes and Prevention of Blindness" recently in session. The report of this Committee has now been published, and mav be obtained from one of His Majesty's Stationery Offices.

\title{
Nettleship Memorial Volume
}

The Francis Galton Laboratory at the University of L.ondon have recently issued an important publication as a memorial to the late Edward Nettleship. The present issue deals with only a few of the diseases in which Nettleship was interested, and it is hoped that a further volume may appear later, dealing with the inheritance of colour blindness, a subject on which, as all our readers know, Nettleship did a very great amount of work. The volume issued is prefaced by an admirable memoir on Edward Nettleship by Mr.J. B. Lawford. The subjects dealt with in this part are retinitis pigmentosa and allied diseases, congenital stationary night blindness, including, of course, the well-known Nougaret family, and glioma retinae. An excellent photograph of Mr. Nettleship forms the frontispiece, and there are reproductions of Usher's ophthalmic pictures of that very rare condition, choroideremia and twenty-six plates of pedigrees of eye disease. The book will prove a valuable one to all interested in inheritance of eye disease and in Mr. Nettleship's work thereon, and we must congratulate Dr. Julia Bell and the Francis Galton Laboratory on having made this work available in such a beautiful form. It must depend on the support that this publication receives whether the work can be continued or not. Unfortunately the production of such a work, which can only have a limited sale, is costly and the price is a little on the high side. 